International Journal of Engineering \& Technology, $7(2.8)(2018) 82-85$
International Journal of Engineering \& Technology
WPC
Website: www.sciencepubco.com/index.php/IJET
Research Paper

\title{
A framework for assessing quality of a web site
}

\author{
M. Vamsi Krishna ${ }^{1}{ }^{*}$, K.Kiran $_{\text {Kumar }}{ }^{2}$, CH.Sandiliya ${ }^{1}$, K.Vijaya Krishna ${ }^{1}$ \\ ${ }^{1}$ Department of ECSE, Koneru Lakshmaiah Education Foundation, Vaddeswaram, Guntur, Andhra Pradesh, India 522502 \\ ${ }^{2}$ Professor, Department of ECSE, Koneru Lakshmaiah Education Foundation, Vaddeswaram, Guntur, Andhra Pradesh, India 522502 \\ *Corresponding author E-mail: kiran5434@kluniversity.in
}

\begin{abstract}
The greater part of the data spread is occurring through Web locales and Web gateways. The adequacy and effectiveness with which data can be spread is especially reliant on the nature of the WEB webpage. The more the nature of a site/entryway, the more refined data can be made accessible to the client. In this manner it ends up noticeably important to characterize quality and furthermore decide the components that measure the nature of site. A quality factor should stick point to a specific part of the web architecture. It is additionally essential to characterize the sort of change that must be attempted for enhancing nature of the site from the perspective of a specific angle.

This paper is principally cantered around deciding terrifically imperative quality factors that can consolidated mirror the aggregate quality and in addition nature of a specific part of web composition. This paper additionally gives a base utilizing which various types of upgrades that ought to be made all together that the nature of the Web website will significantly be improved. Websites are a piece of our regular day to day existence and are utilized to trade and to pass on data between client groups. Passed on data comes in various kinds, dialects and shapes and fuses content, pictures, sound, and video expected to illuminate, induce, offer, show a perspective or even change a demeanour or conviction. Regardless of site multiplication, appraisal of site quality remains a testing region of research. Quality identifies with consumer loyalty and furthermore with the level of achievement of client desire while interfacing a site.
\end{abstract}

Keywords: Quality; Assessment; System; WEB Locales; Computational Methods.

\section{Introduction}

Sites are a piece of our regular day to day existence and are utilized to trade and to pass on data between client groups. Passed on data comes in various kinds, dialects and shapes and joins content, pictures, sound, and video planned to advise, induce, offer, show a perspective or even change a disposition or conviction. In spite of site expansion, evaluation of site quality remains a testing region of research. Quality identifies with consumer loyalty and furthermore with the level of achievement of client desire while interfacing a site. The nature of a site can be evaluated utilizing some quality factors, for example, Usability, Reliability, Flexibility, Functionality, Portability Maintainability, Privacy, Security, Adequacy of Information, Safety, Content, Navigation and so on ....The nature of site can be surveyed from numerous points of view. The appraisal should likewise be possible utilizing assessment tools. Some sites are created by associations that require logo, shading plan, enlivened designs, mouse-over impacts, realistic workmanship, availability with the databases and a few different necessities. Consequently coming about, high expenses and extreme time competing. In request to assess the nature of a site, various endeavours at assessment of customer situated sites have been produced. Some were in a simply subjective type of individual inclinations of the assessor, and some were in the target type of factual estimation, for example, observing the download time of the website and webpage traffics. Site Quality (or Quality of Websites) could be estimated from two points of view: Programmers, and End-clients. The parts of site quality from developers concentrate on the level of Maintainability, Security, Functionality, and so forth. While the end-clients are paying more considerations to
Usability, Efficiency, Creditability, etc.One of the essential objective for site quantitative assessment is to comprehend the degree which a given gathering of value qualities satisfies a chose set of necessities with respect to a particular client see. From one perspective, site spaces like electronic trade, exhibition halls, scholarly locales, and so forth., are winding up progressively complex frameworks. Consequently, an essential quantitative assessment process in regards to all applicable quality attributes is additionally a perplexing issue. The assessment many-sided quality is caused by the expansive measure of interceding attributes and properties, and by the mind boggling rationale connections among traits and attributes. Moreover, some pertinent credits to assess can't impartially be estimated with the goal that exclusive can be incorporated after a subjective estimation made by master evaluators. While examining about the quality appraisal criteria, an arrangement of value parameters is required that characterizes what is normal from the site attributes. The arrangement of site attributes and the relationship among them is considered as the base for framing a quality evaluation display. Besides, to assess the nature of sites, it is important to investigate which quality parameters to consider, which sort of assessment technique to use and which perspectives

of clients are to be considered for the assessment reason.

\section{Literature survey}

Miss. KausarFiaz Khawaja1 et al., [1] have managed factors that incorporate Usability, Privacy Security, and Adequacy of data and Appearance which can be utilized for assessing the nature of a WEB site. Usability is the convenience and learn ability of a hu- 
man-made question, for example, an instrument or gadget. It depicts the nature of client encounter crosswise over websites. Appearance implies the deceivability of the WEB webpage which incorporates engaging, cleaned and proficient introduction. Ampleness of Information implies Putting adequate and valuable data in the site. A strategy has been introduced paper that helps figuring the quality in light of the perceptions made while the WEB webpage is being used.

Vijay kumarMantri et al. [2], have exhibited that nature of a WEB webpage can be processed utilizing the elements, for example, Usability, Safety and Flexibility. Ease of use of a site must be successful, effective and acceptable. Wellbeing of a Website must guarantee that no association of a client with the WEB webpage could be ever uncovered. Adaptability is the capacity to in clude/change/evacuate usefulness influencing the WEB pages without harming the working of current continuous framework. The creators have utilized an apparatus called Portal Data Quality Assessment Tool (PoDQA) utilizing a quality model called Portal Data Quality Model (SPDQM).

Vassilis S. Moustakis et al., [3] have utilized the quality variables which incorporate Content, Navigation, Structure and Design, Appearance, Multimedia, Uniqueness. Content is the data passed on to the end client through a UI. Content reflects quality, culmination, level of specialization or speculation and dependability of data incorporated into the site. Route mirrors the help gave to the client while moving in and around the site. Components of route incorporate ease of moving around, effortlessness in understanding site structure, and accessibility and legitimacy of connections. Structure and Design fuses viewpoints that influence request of introduction, speed and program. Appearance and Multimedia catches angles that identify with site's "look and feel" with unique accentuation on the best in class illustrations and sight and sound antiquities. Uniqueness alludes to client's recognition that the site conveys something that makes it distinctive in a world loaded with locales. A computational strategy called AHP (Analytical Hierarchical Process) has been utilized for figuring nature of a site.

AndrinaGraniü et al., [4] have exhibited the nature of a WEB webpage from the purpose of portability. Portability implies the capacity to move the site starting with one host stage then onto the next and the stage that runs the website will take a shot at the new host.

Tanya Singh et al. [5], have utilized quality factors that incorporate Usability, Privacy and Security, Adequacy of data and Appearance. Usability is the convenience and learns ability of a human-made question, for example, an instrument or gadget. It depicts the nature of client encounter crosswise over sites. Protection is tied in with uncovering data to those clients who are distinguished by the proprietor of the client. Just chose clients are furnished with the data of those information components expected to be shared by the proprietor of the information. Security is tied in with protecting the communication of the client with the WEB website. Sufficiency of data is identified with making accessible finish information with no remaining details that do the trick the genuine necessities of the end client. Appearance of a WEB website is tied in with showing the substance in most justifiable by utilizing hues. Designs, groupings and so on.

\section{Investigations and findings}

Numerous Authors have exhibited a few factors that can be utilized for surveying the nature of any site. Be that as it may, next to no work has been introduced identified with the way the quality viewpoints have been estimated and no observational formulae accordingly could be recommended in view of which one will have the capacity to register the nature of a site in general. Each WEB website is fabricated utilizing a few highlights. The nature of the WEB website as entire must be processed by expansion of nature of the whole individual quality factor that matches an element of a site. The references to the creators who have prescribed the quality components have been introduced in Table 1. No crea- tor all things considered has exhibited exact equations utilizing which the Quality of the WEB destinations can be processed. Diverse kinds of techniques that can be utilized for registering the nature of various elements are appeared in Table 2.

The observational plans of the same have likewise been introduced in the Table. A Feature of a site could be viewed as poor, low, normal and top notch in light of the figured estimations of the quality factor. Weight age for each of the factor could be viewed as in light of the esteem processed for each of the factor registered. The quality Grading is appeared in Table 2. A complete rundown of highlights that can be bolstered for building up a WEB webpage is appeared in Table 3. The rundown of value factors that matches the highlights of the WEB webpage are appeared in Table 3. One can process the nature of a WEB webpage subsequent to knowing the highlights of the WEB website and the way the highlights have been executed. Table 4 demonstrates the highlights upheld on specific site alongside quality elements mapping and calculation of the nature of the WEB website. Correlation of value estimations with limit esteem will demonstrate the shortcomings that are bearing on the WEB webpage. Regularly enhancing the WEB webpage for guaranteeing the quality estimation that meet the limit esteem will prompt the improvement of top notch WEB website. Add up to quality level can be figured by including the nature of each factor. The over nature of a site can be acquired by dividing the aggregate quality by the quantity of highlights bolstered by the site decided for calculation.

Total Number of Features $=25$

Sum of quality Gradations $=17.45$

Average Total Gradation $=17.45 / 25=3.49 / 4=87 \%$

(Quality of the chosen web site which can be accepted when minimum level of acceptable level of quality is $>75 \%$.

\subsection{Experimental investigations}

\section{Plausibility study}

The plausibility of the venture is broke down amid this segment and business proposition is put forward with an outrageously broad set up for the undertaking and a couple of value gauges. all through framework examination the achievability investigation of the anticipated framework is to be administered. This is regularly to ensure that the anticipated framework isn't a weight to the corporate. For practicality investigation, some comprehension of the principle requirements for the framework is imperative.

Three key contemplations engaged with the practicality investigation are

\section{- Economical Feasibility \\ - Technical Feasibility \\ - Social Feasibility}

Economical feasibility

This investigation is done to check the monetary effect that the framework will have on the association. The measure of store that the organization can fill the innovative work of the framework is restricted. The uses must be legitimized. Therefore the created framework too inside the financial plan and this was accomplished on the grounds that a large portion of the advances utilized are openly accessible. Just the redid items must be obtained.

Technical feasibility

This examination is administrated to analyze the specialized practicableness, that is, the specialized needs of the framework. Any framework created ought not to have popularity on the reachable specialized assets. This may bring about levels of popularity on the possible specialized assets. This may bring about levels of popularity being set on the customer. The created framework ought to have a humble request, as exclusively insignificant or invalid changes are required for actualizing this procedure.

Social feasibility

The feature of study is to determine the degree of acknowledgment of the framework by the client. This incorporates the strategy for instructing the client to utilize the framework with proficiency. The client ought not feel defenceless by the framework, rather should make do with it as a need. The degree of acknowledgment 
by the clients alone relies upon the techniques that square measure used to instruct the client with respect to the framework and to make him familiar with it. His level of certainty ought to be brought up all together that he's conjointly ready to make some productive feedback that is welcome, as he's a definitive client of the framework.

\section{System requirements}

\subsection{Software requirements}

- Operating system: any operating system with visual studio 2013.

- Coding Language: c\#, dot net, java script.

- Data Base: my SQL server.

\section{Output}
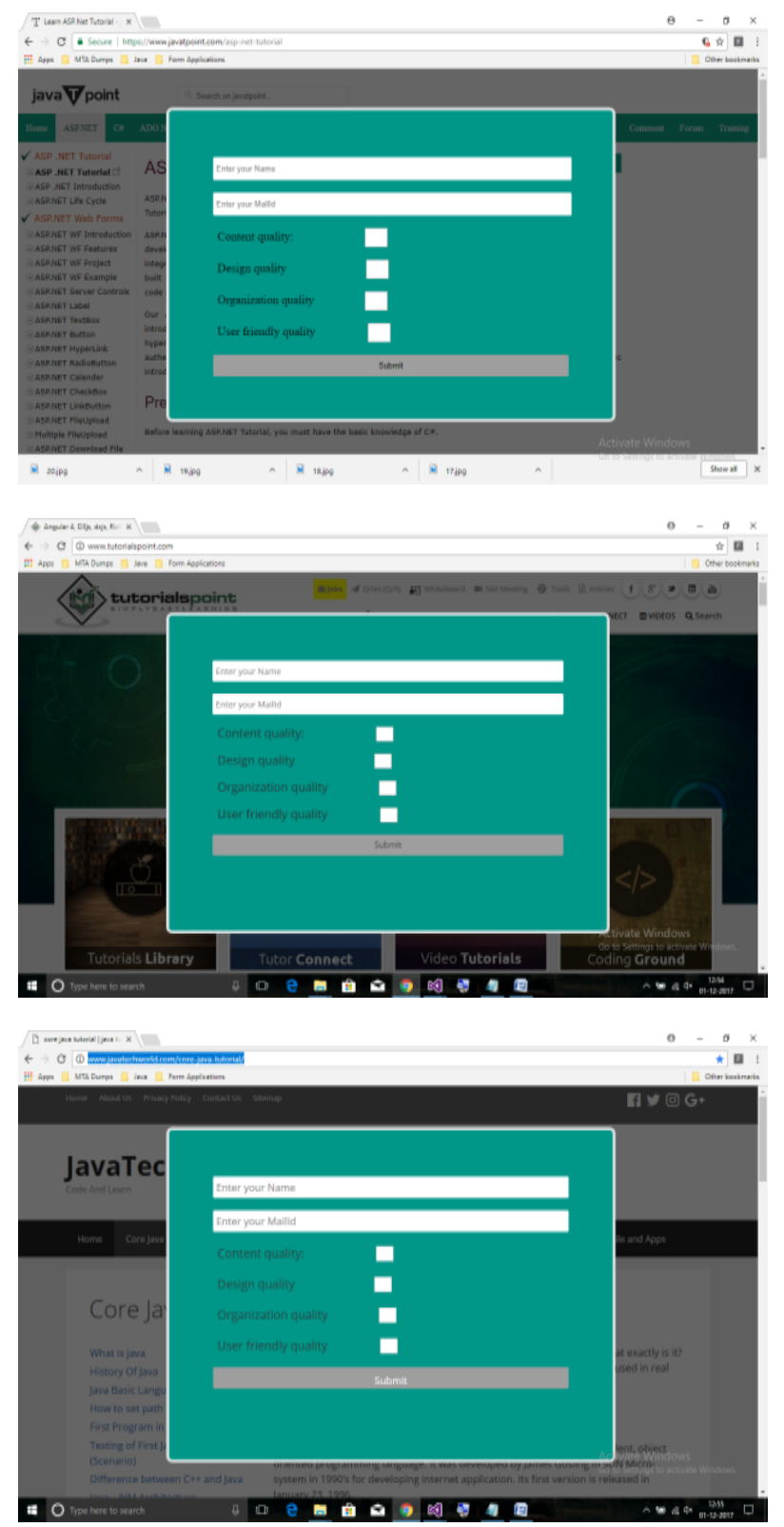

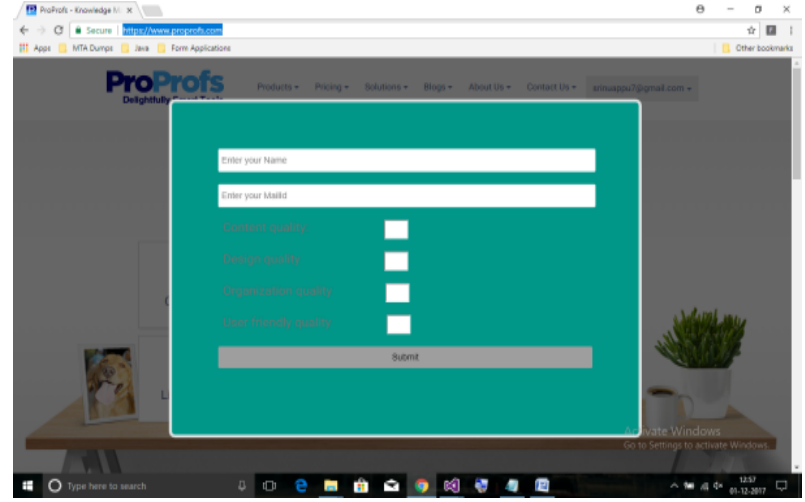

\section{Experimental results}

Despite the fact that testing partner examination structure typically won't not be a one-time undertaking, the after-effects of the contextual analysis amid this Thesis work demonstrated that the new system is more down to earth than the base model for assessing the standard of instructive sites from the code clients point of view. this can be inferable from the very truth that the new investigation structure comprises of value qualities that region unit significant for school children to utilize instructive sites. This can be appeared inside the investigation after-effects of the TUDelft site. Abuse the anticipated quality investigation show; it totally was potential to gauge the basic properties of the site like substance of the site, while this wasn't potential inside the base model. The consequences of the contextual analysis gave a motivation of that qualities of the TU-Delft site understudies assume might want change; particularly a cautious research the substance, common sense and esteem attributes of the site is vital. Additionally, from the consequences of the contextual investigation, it completely was resolved that the hierarchal game plan of the standard factors and sub factors inside the anticipated system looked as though it would be higher than that of the base model, ISO 9126-1. In any case, more investigation should be made on the various levelled information structure of the standard factors and sub factors. Upheld the consequences of the reliableness investigation, sub factors, for example, expert, personality, different dialect bolster extraordinarily demonstrated deviations or irregularities from the rest of the components and more work should give weight on preparing these variables. Since this Thesis limited itself to the perspectives of successive clients of instructive sites (understudies), the standard components like portability and practicality, that territory unit a piece of the base model, weren't thought of inside the new structure and along these lines inside the contextual investigation. The fifty five understudies World Health Organization took an interest inside the contextual investigation were from indistinguishable school and those them extra or less have a similar foundation of study. These could affect the results of the reactions assembled and along these lines the consequences of the shape. Hence leading a similar report by including understudies from very surprising schools and offices is justified, despite all the trouble. Site quality investigation is frequently done at any phases of site style [2]. Eightieth of cost in thinking of sites and keeping up them is spent once the arranging and execution of web locales. Studies direct that these extent cost are regularly lessened by assessing the site at each phase of the site style cycle [10]. The idea is that the site style undertaking is done in enduring cycles. In each cycle, the site is tried, and refined, wherever the testing yield of 1 cycle encourages to following cycle prompting an item with relate enhanced quality. Figure 14: unvaried site design cycle [13] as appeared inside the outline higher than, thinking of a site incorporates relate unvaried conditions of exercises, which joins the plan actualize assess stages. In lightweight of this idea, the examination exercises at each phase of the arranging lifecycle of \{a web site|an web site|a web site \} should join clients' wants and interests inside the site. 


\section{Conclusion}

Data scattering and trade among broadly scattered clients is just conceivable through execution of WEB destinations. The greater part of the organizations nowadays are reliant on WEB website for correspondence with the clients for either conveying e-promoting or completing an online business based business. The quality with which a WEB website is fabricated assumes a fundamental part understanding the advantages of creating and executing a WEB webpage. No computational strategies or a general structure has been proposed so far to either register quality or give a premise of upgrading the nature of the WEB webpage. In this paper general structure and computational strategies have been introduced utilizing which nature of a WEB webpage is figured.

\section{Future scope}

Research Literature expounds information quality or data quality as a critical factor and is relies upon the system where it is utilized. There is radical increment in number of online interfaces and their uses in everyday life by clients for critical work in a decade ago. The accomplishment of gateway relies upon number of clients utilizing the entrance attractively. The nature of data accessible on these web-based interfaces is especially essential. The different models accessible utilized diverse criteria, distinctive strategies for quality assessment of online interface which are perplexing in nature. There are few models which are great and furthermore there is vagueness exhibit in different models accessible. There is need of good online interface quality assessment display which is extremely identified with great quality attributes of web-based interface. We propose a web-based interface quality assessment display utilizing Six Sigma \&Analytical Hierarchy Process (AHP). The Six Sigma takes after five stages strategy Define, Measure, Analyze, Design and Validate (DMADV) to build up a quality assessment show for web-based interface quality assessment. The AHP encourages leader to locate the best procedure that suits their objective and their comprehension of the issue. It gives a complete and discerning system for organizing a choice issue, for speaking to its qualifying components, for relating those components to general objectives, and for assessing elective answers for online interface quality assessment. Our proposed display is characterized utilizing few properties which assume critical part in nature of data accessible on Web entrance. The model is complete and simple method for estimation to be utilized for quality assessment of Web Portal.

\section{References}

[1] Miss. KausarFiaz Khawaja1, Dr.RahatHussain Bokhari2, Exploring the Factors Associated With Quality of Website Department of Technology Management, International Islamic University, Islamabad, Pakistan, Vol.10, Issue 14 November 2010, Pg37-45.

[2] VijaykumarMantri, Dr. S. Kalaimagal, Dr N.Srinivasu,An Introspection of Web Portals Quality Evaluation,Vol.5, No.9,DOI:10.15693/ijaist/2016.v5i9.33-38.

[3] Vassilis S. Moustakis1,2, Charalambos Litos1, Andreas Dalivigas1, and Loukas Tsironis1, Website quality assessment criteria, Proceedings of the Ninth International Conference on Information Quality , 2004

[4] AndrinaGraniü, IvicaMitroviü* and Nikola Maranguniü, Usability Evaluation of Web Portals, Proceedings of the ITI 2008 30th Int. Conf. on Information Technology Interfaces, June 23-26, 2008

[5] Tanya Singh, SachinMalik,DarothiSarkar,E-Commerce Website Quality Assessment based on Usability,Department of Computer Science \& Engineering Amity University Uttar Pradesh Noida, India Pg101-105.

[6] R.Anusha,A Study on Website Quality Models,Department of Information Systems Management, M.O.P Vaishnav College For Women(Autonomous), Chennai,Volume 4,Issue 12, December 2014,Pg:1-5.
[7] FilippoRicca and Paolo Tonella,Analysis and Testing of Web Applications,Centro per la RicercaScientifica e Tecnologica, I-38050 Povo (Trento), Italy,

[8] Saleh Alwahaishil and Václav Snášel2, Assessing the LCC Websites Quality, (C) Springer-Verlag Berlin Heidelberg 2010, F. Zavoral et al. (Eds.): NDT 2010, Part I, CCIS 87, 2010, pp. 556-565.

[9] Layla Hasan1 and EmadAbuelrub, Assessing the Quality of Web Sites, Applied Computing and Informatics, Volume 9, Issue 1, January 2011, Pages 11-29

[10] Kavindra Kumar Singh, Dr. Praveen Kumar, JitendraMathur, Implementation of a Model for Websites Quality Evaluation - DU Website, International Journal of Innovations \& Advancement in Computer Science IJIACS ISSN 2347 - 8616 Volume 3, Issue 1 2014

[11] Long-Sheng Chen1, and Pao-Chung Chang, Identifying Crucial Website Quality Factors of Virtual Communities, Proceedings of the International Multi-Conference of Engineers and computer scientists, Vol 1, IMECS 2010.

[12] Naw Lay Wah, An Improved Approach for Web Page Quality Assessment, IEEE Student Conference on Research and Development, 2011.

[13] Dr. Seetaiah Kilaru, Hari Kishore K, Sravani T, Anvesh Chowdary L, Balaji T "Review and Analysis of Promising Technologies with Respect to fifth Generation Networks", 2014 First International Conference on Networks \& Soft Computing, ISSN:978-1-47993486-7/14,pp.270-273,August2014.

[14] Meka Bharadwaj, Hari Kishore "Enhanced Launch-Off-Capture Testing Using BIST Designs" Journal of Engineering and Applied Sciences, ISSN No: 1816-949X, Vol No.12, Issue No.3, page: 636643, April 2017.

[15] P Bala Gopal, K Hari Kishore, B.Praveen Kittu "An FPGA Implementation of On Chip UART Testing with BIST Techniques", International Journal of Applied Engineering Research, ISSN 09734562, Volume 10, Number 14 , pp. 34047-34051, August 2015.

[16] A. Murali, K Hari Kishore, D Venkat Reddy "Integrating FPGAs with Trigger Circuitry Core System Insertions for Observability in Debugging Process" Journal of Engineering and Applied Sciences, ISSN No: 1816-949X, Vol No.11, Issue No.12, page: 2643-2650, December 2016.

[17] Mahesh Mudavath, K Hari Kishore, D Venkat Reddy "Design of CMOS RF Front-End of Low Noise Amplifier for LTE System Applications Integrating FPGAs" Asian Journal of Information Technology, ISSN No: 1682-3915, Vol No.15, Issue No.20, page: 40404047, December 2016

[18] N Bala Dastagiri, K Hari Kishore "Novel Design of Low Power Latch Comparator in 45nm for Cardiac Signal Monitoring", International Journal of Control Theory and Applications, ISSN No: 0974-5572, Vol No.9, Issue No.49, page: 117-123, May 2016.

[19] N Bala Gopal, Kakarla Hari Kishore "Reduction of Kickback Noise in Latched Comparators for Cardiac IMDs" Indian Journal of Science and Technology, ISSN No: 0974-6846, Vol No.9, Issue No.43, Page: 1-6, November 2016.

[20] S Nazeer Hussain, K Hari Kishore "Computational Optimization of Placement and Routing using Genetic Algorithm" Indian Journal of Science and Technology, ISSN No: 0974-6846, Vol No.9, Issue No.47, page: 1-4, December 2016.

[21] N.Prathima, K.Hari Kishore, "Design of a Low Power and High Performance Digital Multiplier Using a Novel 8T Adder", International Journal of Engineering Research and Applications, ISSN 2248-9622, Vol. 3, Issue.1, Jan-Feb., 2013.

[22] Harikishore Kakarla, Madhavi Latha M and Habibulla Khan, "Transition Optimization in Fault Free Memory Application Using Bus-Align Mode", European Journal of Scientific Research, Vol.112, No.2, pp.237-245, ISSN: 1450-216x135/1450-202x, October 2013

[23] T. Padmapriya and V. Saminadan, "Improving Throughput for Downlink Multi user MIMO-LTE Advanced Networks using SINR approximation and Hierarchical CSI feedback", International Journal of Mobile Design Network and Innovation- Inderscience Publisher, ISSN : 1744-2850 vol. 6, no.1, pp. 14-23, May 2015.

[24] S.V.Manikanthan and K.srividhya "An Android based secure access control using ARM and cloud computing", Published in Electronics and Communication Systems (ICECS), 2015 2nd International Conference on 26-27Feb. 2015, Publisher: IEEE, https://doi.org/10.1109/ECS.2015.7124833. 